\title{
A systematic review and meta-analysis of safety and efficacy of safinamide for motor fluctuations in patients with
} Parkinson's disease [version 1; peer review: 2 approved, 1 approved with reservations]

\author{
Mohamed Abdelalem Aziz Ahmed (D)
}

School of Advanced Education Research and Accreditation, Universidad Isabel I, Burgos, Spain

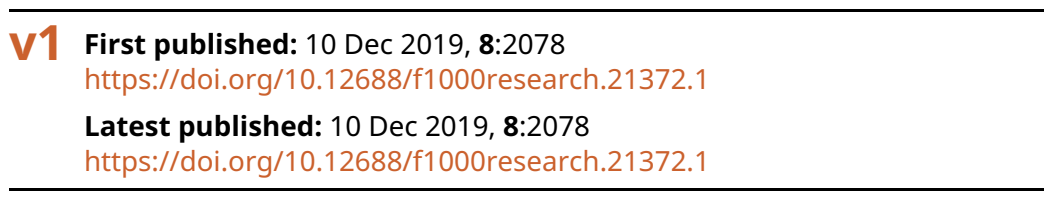

\section{Abstract}

Background: Safinamide, a recently developed drug with several mechanisms of action has been investigated as an add-on therapy for Parkinson's disease patients suffering from motor complications due to the usage of anti-Parkinson's medications such as levodopa and dopaminergic drugs. The aim of the study is to investigate the efficacy and safety of Safinamide as add-on therapy for Parkinson's disease patients.

Methods: A computerized literature search was conducted of PubMed, EMBASE, ClinicalTrial.gov and Cochrane Library until August 2019. We selected relevant randomized controlled trials comparing safinamide groups to placebo groups. Relevant outcomes were pooled as mean difference (MD) and risk ratio (RR) using Review Manager 5.3.

Results: We found that the overall MD of changes in "off-time" and "on time without troublesome dyskinesia" favored the safinamide group over the placebo group (MD -0.72 h, 95\% CI -0.89 to -0.56 and MD $0.71 \mathrm{~h}, 95 \%$ CI 0.52 to 0.90 , respectively). Additionally, the overall MD of change in Unified Parkinson's Disease Rating Scale part three (UPDRS III) favored the safinamide group (MD -1.83, 95\% CI -2.43 to 1.23). In case of adverse events, the pooled meta-analysis did not favor the safinamide group over the placebo group.

Conclusions: In this study, we provide class I evidence about the potential role of safinamide as an add-on therapy for Parkinson's disease patients suffering from motor fluctuations. However, a few included studies did not mention the data of important outcomes. Also, we report high risk of bias in individual studies. Future randomized controlled trials with different doses are recommended to provide more evidence for the efficacy and safety of safinamide as a treatment for motor complications of anti-Parkinson's medications.

\section{Open Peer Review}

\begin{tabular}{cccc} 
Approval Status & $?$ \\
& 1 & 2 & 3 \\
\hline version 1 & $?$ & $\checkmark$ & \\
10 Dec 2019 & view & view & view \\
\hline
\end{tabular}

1. Fabrizio Stocchi, IRCCS San Raffaele Pisana, Rome, Italy

\section{Rupam Borgohain, Nizam's Institute of} Medical Sciences, Hyderabad, India Rukmini Kandadai, Nizam's Institute of Medical Sciences, Hyderabad, India

3. Ahmed Negida, University of Portsmouth, Portsmouth, UK

Zagazig University, Zagazig, Egypt

Any reports and responses or comments on the article can be found at the end of the article. 
Keywords

Safinamide, Parkinson's disease, Motor, Dopamine agonist, Movement disorder, UPDRS, Dopamine, Add-on

Corresponding author: Mohamed Abdelalem Aziz Ahmed (mohamedabdelalem@med.menofia.edu.eg)

Author roles: Abdelalem Aziz Ahmed M: Conceptualization, Formal Analysis, Funding Acquisition, Methodology, Supervision, Validation, Visualization, Writing - Original Draft Preparation, Writing - Review \& Editing

Competing interests: No competing interests were disclosed.

Grant information: The author(s) declared that no grants were involved in supporting this work.

Copyright: $\odot 2019$ Abdelalem Aziz Ahmed M. This is an open access article distributed under the terms of the Creative Commons Attribution License, which permits unrestricted use, distribution, and reproduction in any medium, provided the original work is properly cited.

How to cite this article: Abdelalem Aziz Ahmed M. A systematic review and meta-analysis of safety and efficacy of safinamide for motor fluctuations in patients with Parkinson's disease [version 1; peer review: 2 approved, 1 approved with reservations] F1000Research 2019, 8:2078 https://doi.org/10.12688/f1000research.21372.1

First published: 10 Dec 2019, 8:2078 https://doi.org/10.12688/f1000research.21372.1 


\section{Introduction}

Parkinson's disease prevalence in the fourth decade of life is 41 people per 100,000 and increases to 1,900 people per 100,000 among those who are older than $80^{1}$. According to these statistics, Parkinson's disease is the second most common neurodegenerative disease after Alzheimer's disease.

The main pathology of Parkinson's disease is loss of dopaminergic innervation in the nigrostriatal pathway and spread to various regions in the brain. This loss leads to two types of symptoms; motor and non-motor. Motor symptoms include tremors, rigidity, and bradykinesia. Non-motor symptoms include depression, inability to sustain attention, and sometimes psychosis, especially hallucinations.

Despite the recent medications and updates in the field of pharmacology, there is no definitive treatment that can stop the progress of dopamine receptor loss in the nigrostriatal pathway. Therefore, we only use symptomatic medications for both the motor and non-motor symptoms.

The main symptomatic medications of Parkinson's disease are Levodopa (L-Dopa) ${ }^{2,3}$, dopamine agonists (DAs), and monoamine oxidase-B (MAO-B) inhibitors. Unfortunately, increasing the dose of these medications, especially L-Dopa, leads to motor side effects such as end-of-dose wearing off and dyskinesia, which can be irritating for patients ${ }^{4-6}$. Recently, a novel drug called safinamide was developed, which can reduce the side effects of these symptomatic medications, especially motor adverse events.

Safinamide has several dopaminergic and non-dopaminergic mechanisms of action such as sodium channel blockade, calcium channel modulation, and MAO-B inhibition? ${ }^{7}$. The main goal of these mechanisms is inhibiting glutamate release and subsequently, improving motor symptoms ${ }^{8}$.

Recently published studies discussed the beneficial role of safinamide for treatment of motor complications of Parkinson's medications ${ }^{9-14}$. Some of them suggest that usage of safinamide improves quality of life and delays the motor deterioration of Parkinson's disease; thus, our study aims to evaluate the safety and efficacy of safinamide use for Parkinson's patients. According to our knowledge, this is the first meta-analysis that provides class I evidence for the useful usage of Safinamide for Parkinson's motor complications.

\section{Methods}

The Preferred Reporting Items of Systematic reviews and Meta-Analyses (PRISMA) guidelines were followed during the preparation of this manuscript ${ }^{15}$. We specified the inclusion criteria, methods of searching, and analysis in advance. The methods and analyses were conducted in strict accordance to the guidelines of the Cochrane Handbook for Systematic Reviews of Interventions and the Methods Guide for Comparative Effectiveness Reviews ${ }^{16,17}$.

\section{Eligibility criteria}

Studies that fit all of the following criteria were included in the meta-analysis:

(1) Population: Studies whose population was patients with idiopathic Parkinson's disease (diagnosed using the UK Parkinson's Disease Society Brain Bank Criteria) ${ }^{18}$ and including all stages of Parkinson's disease (mid to late stages)

(2) Intervention: Studies where patients receive safinamide as an experimental drug (all doses are considered) and continue receiving dopamine agonist treatment

(3) Comparator: Studies where the control group received a placebo

(4) Study design: Studies that were described as prospective randomized controlled trials

Studies were excluded based on the following criteria:

(1) Studies using drugs other than safinamide as experimental drugs

(2) Studies not using safinamide ass add-on therapy for motor fluctuations in Parkinson's disease

(3) Animal studies, in vitro studies, case reports/case series, conference abstracts, or review articles

(4) All studies other than randomized controlled trials (case reports, conference abstracts, and review articles)

(5) Studies unavailable in the English language.

\section{Information source and literature search}

A computer literature search was performed of online databases: PubMed, EMBASE, ClinicalTrial.gov and the Cochrane Library from 1960 to the end of August 2019 (the time of the last search) using the following keywords: ("Safinamide"[All Fields]) AND ("Parkinson disease"[MeSH Terms] OR ("Parkinson"[All Fields] AND "Disease"[All Fields]) OR "Parkinson disease"[All Fields] OR ("Parkinson's"[All Fields] AND "Disease"[All Fields]) OR "PD"[All Fields]). No restrictions by language or publication period were used.

\section{Study selection}

After removal of duplicate articles, two reviewers (M.H and R.G) screened a spreadsheet of titles and abstracts independently using Microsoft Excel 2013 (windows version). Full text studies selected were examined independently by the same two reviewers, the third reviewer (A.N) solve any disagreement by discussion with the main author before the final selection. The independent reviewers are acknowledged for their generous help in searching, screening, and data extraction processes. We did not need to contact any study investigator for further clarification.

\section{Data collection process and data items}

An online data extraction sheet was constructed. One independent reviewer (M.H) extracted the data from included studies and 
entries were checked by the main author. The data extraction form included the following domains: 1) study ID; 2) year of publication; 3) country; 4) study design (randomized controlled trials only); 5) follow-up duration; 6) safinamide dose; 7) population definition; 8) inclusion and exclusion criteria; 9) sample size; 10) baseline characteristics; 11) available data of outcome measures (pre, post, and change from baseline); and 12) quality assessment domains. A copy of data extraction form is available as extended data ${ }^{19}$.

\section{Risk of bias in individual studies}

Cochrane risk of bias assessment tool was used to assess the risk of bias in randomized controlled trials. We assessed the following risks: 1) Selection bias; 2) performance bias; 3) detection bias; 4) attrition bias; 5) reporting bias; and 6) any other source of bias that might have influenced the study data ${ }^{20}$. One reviewer (A.N) and the main author rated each domain separately as low, high or unclear risk of bias. We used Review Manager software (RevMan 5.3) to summarize the risk of bias of included randomized controlled trials.

\section{Efficacy measures}

The efficacy of drugs treating motor complications in Parkinson's disease was assessed for the following outcomes:

(1) Unified Parkinson's Disease Rating Scale part three (motor part) (UPDRS III): The unified Parkinson's disease rating scale ${ }^{21}$ is a reliable score of four parts to assess the severity of Parkinson's symptoms. Part three indicates the motor score, which is the main measure for motor function in Parkinson's disease patients.

(2) Patient-reported diaries: Patient diaries gave information about the duration of the following motor outcomes: "on time with non-troublesome dyskinesia", which means the duration of absence of dyskinesia associated with the long term usage of Parkinson's dopaminergic drugs such as levodopa and "off-time", which is the duration of returning motor and non-motor symptoms of Parkinson's disease, even with the use of levodopa and other antiparkinsonian drugs.

(3) Dyskinesia Rating Scale (DRS): Long term usage of dopaminergic drugs leads to involuntary motor movements. This scale is one of the best scales to assess these motor complications ${ }^{22}$. It measures the following outcomes: "on time dyskinesia" and "off-time dyskinesia". Additionally, it gives recommendations for descriptions of each type of involuntary movement that can be used when talking with people affected by Parkinson's.

(4) Clinical Global Impression scale - Severity of Illnes (CGI-S): A seven-point scale used to measure symptom severity, efficacy of the treatments, and treatment response in studies containing patients with mental health issues ${ }^{23}$.

(5) Unified Parkinson's Disease Rating Scale part two (UPDRS II): UPDRS is the most commonly used scale to assess the clinical condition of Parkinson's disease. This is the second part of UPDRS scale, which is used to evaluate the activities of daily life (ADLs) such as hygiene, speech, dressing, and swallowing ${ }^{24}$.

(6) Parkinson's Disease Questionnaire (PDQ-39): A selfreported questionnaire with 39 items $^{25}$. This questionnaire is mainly used to evaluate the difficulties Parkinson's disease patients face in eight quality of life dimensions, including ADLs, cognition, attention, working memory, depression, social support, social relationship, and functional mobility.

(7) Mini-Mental State Examination (MMSE) scale: A 30point questionnaire used mainly to evaluate cognitive function. Its usage includes the following: estimating disease progression, severity of impairment of cognitive functions, and documenting the response of mental ill patients to treatment ${ }^{26}$.

(8) Hamilton Depression Rating Scale (HAM-D): A 21-item test widely used in clinical practice and pharmaceutical trials to assess depressive symptoms ${ }^{27}$.

Synthesis of results

Since all the data in the study are continuous data, each efficacy measure is reported as mean difference (MD) between the two groups from the baseline to endpoint, along with its standard error (SE). Both were pooled using the DerSimonian-Laird random effect model. In the case of studies reporting data at multiple time points, the last endpoint was considered.

The overall MD was interpreted with the consideration that efficacy measures are in different directions; an improvement in "on time without troublesome dyskinesia" would be indicated by an increased MD, while an improvement in UPDRS III, "off-time", UPDRS II, DRS, PDQ-39, MMSE, and HAM-D scores would be indicated by a decreased MD.

The proportion of risk ratio (RR) was used to pool the adverse events reported in the studies to the total number in each group between the two groups in the DerSimonian-Laird random effect model. To examine heterogeneity of studies, forest plot visual inspection was used and assessed using the Cochrane $Q$ and I 2 tests using RevMan version 5.3 for windows.

\section{Calculation of missing data}

A few studies, such as as Stoochi (2004), did not report the MD between the safinamide group and placebo group so it was calculated using the following calculation: $[\mathrm{MD}=\mathrm{MD}$ experimental - MD placebo]. Standard error was calculated from the standard deviation [standard error $=$ standard deviation $/ \downarrow_{n}$ ], $95 \%$ confidence interval [(upper limit - lower limit) 3.92], or 90\% CI [(upper limit - lower limit) 3.29]. For studies and groups with a sample size of less than 60 patients, the numbers (3.92 and 3.29) were substituted by a value from the table of $t$ distributions with degrees of freedom equal to the group sample size minus one.

\section{Risk of bias across studies}

Funnel plots was used to explore the publication bias across studies and to show the relationship between effect size and 
precision. The evidence of publication bias was assessed using the following: 1) Egger's regression test, and 2) the Begg and Mazumdar rank correlation test (Kendall's tau).

\section{Software}

We performed all the analysis and calculations in this meta-analysis using Review Manager software version 5.3 (RevMan 5.3).

\section{Results}

\section{Study selection}

The literature search resulted in 160 studies. After the complete screening process of titles, abstracts, and full texts, 154 studies did not meet the eligibility criteria and six articles with six randomized controlled trials remained with a total of (2556) patients included in the meta-analysis ${ }^{9-14}$.

A description of the flow of study selection is shown in the PRISMA flow diagram in Figure 1.

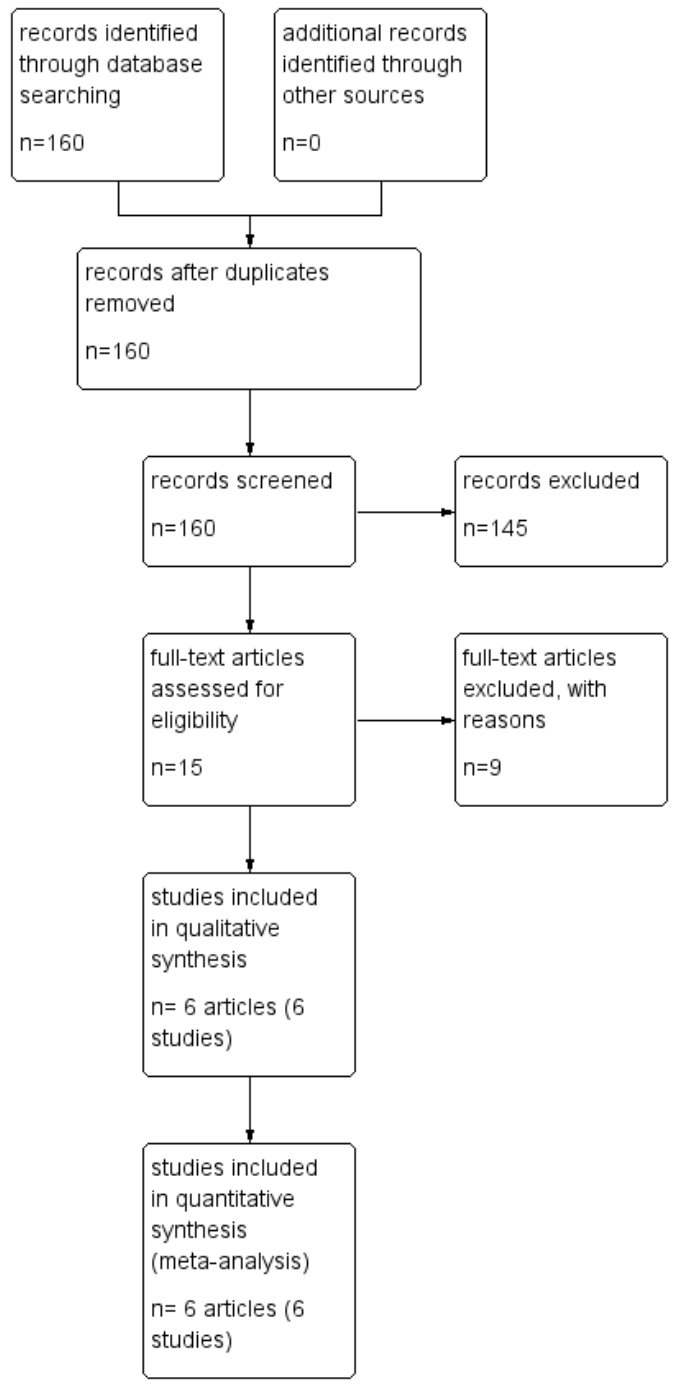

Figure 1. PRISMA flow diagram of the screening and selection for the study.

\section{Study characteristics}

The follow up duration in the studies ranged from 12 weeks in Stoochi et al. (2004) and Stoochi et al. (2011), ${ }^{9,10}$ to 24 weeks in the study by Schapira et al. (2012), Borgohain et al. (2013), Schapira et al. (2016), and Borgohain et al. (2014) ${ }^{11-14}$.

The daily doses of safinamide received in the studies included in the meta-analysis ranged from $40 \mathrm{mg}$ in the study by Stoochi et al. (2004) ${ }^{9}$ to $200 \mathrm{mg}$ in studies by Stoochi et al. $(2011)^{10}$ and Schapira et al. (2012) $)^{11}$. The population of all studies was homogenous and remained on the dopaminergic treatment during the entire study period.

All patients enrolled in the studies were diagnosed with Parkinson's disease according to UK Parkinson's Disease Society Brain Bank Criteria. The criteria of patients excluded from studies were: 1) history of psychiatric disorders, 2) severe and progressive medical illness, 3) patients with dementia, 4) severe dyskinesia. Summary and baseline characteristics of populations of these studies are shown in Table 1.

\section{Risk of bias within studies}

The Cochrane risk of bias assessment tool was used to assess the quality of included studies. All included studies had a low risk of bias in terms of random sequence generation, allocation concealment, blinding of participants and personnel, blinding of outcome assessment, incomplete outcome data, and selective reporting except Schapira et al. (2012) ${ }^{11}$, which had a high risk of bias for random sequence generation as the randomization method was not reported and for the blinding of outcome assessment as the method of blinding was not reported, and Stoochi et al. (2004) ${ }^{9}$, which had a high risk for incomplete outcome data because there was no intention to treat analysis for missed or withdrawn patients mentioned in the study. The summary of risk of bias domains is shown in Figure 2.

\section{Drug efficacy}

Off-time. The overall MD between the two groups from baseline to endpoint in terms of change in "off-time" favored safinamide over placebo (MD -0.72 h, 95\% CI [-0.89 to -0.56], Figure 3A). Pooled studies were homogenous $(\mathrm{P}=0.42)$.

On time without troublesome dyskinesia. The overall MD between the two groups from baseline to endpoint in terms of change in "on time without troublesome dyskinesia" favored safinamide over placebo (MD $0.71 \mathrm{~h}, 95 \%$ CI [0.52 to 0.90], Figure 3B). Pooled studies were homogenous $(\mathrm{P}=0.54)$.

UPDRS III. The overall MD between the two groups from baseline to endpoint in terms of change in "UPDRS III" favored safinamide over placebo (MD -1.83 , 95\% CI [-2.43 to $-1.23]$, Figure $3 \mathrm{C}$ ). Pooled studies were homogenous $(\mathrm{P}=0.80)$.

UPDRS II. The overall MD between the two groups from baseline to endpoint in terms of change in "UPDRS II" favored safinamide over placebo (MD $-0.69,95 \%$ CI [-1.03 to $-0.36]$, Figure 3D). Pooled studies were homogenous $(\mathrm{P}=0.26)$. 


\begin{tabular}{|c|c|c|c|c|c|c|c|c|c|c|}
\hline Study ID & Design & $\begin{array}{l}\text { Final } \\
\text { endpoint }\end{array}$ & Group & $\mathbf{N}$ & Age $^{*}$ & Male \% & UPDRS III* & CGI-S* & MMSE* & HAM-D* \\
\hline \multirow{3}{*}{ Stoochi et al. 2011} & \multirow{3}{*}{$\mathrm{RCT}$} & \multirow{3}{*}{12 weeks } & $\begin{array}{l}\text { Safinamide } \\
200 \text { mg/day }\end{array}$ & 89 & $58.5(11.7)$ & 61 & $19.3(9.80)$ & $3.1(0.85)$ & $28.3(1.54)$ & $4.2(3.11)$ \\
\hline & & & $\begin{array}{l}\text { Safinamide } \\
100 \text { mg/day }\end{array}$ & 90 & 56.5 (11.3) & 66 & $22.0(10.15)$ & $3.1(0.79)$ & $28.9(1.21)$ & $4.0(3.43)$ \\
\hline & & & placebo & 90 & $57.3(10.8)$ & 62 & $20.7(9.63)$ & $3.1(0.76)$ & $28.4(1.56)$ & $4.3(3.22)$ \\
\hline \multirow{3}{*}{ Schapira et al. 2012} & \multirow{3}{*}{$\mathrm{RCT}$} & \multirow{3}{*}{24 weeks } & $\begin{array}{l}\text { Safinamide } \\
200 \text { mg/day }\end{array}$ & 69 & $56.5(25.5)$ & 62.3 & $20.1(10.44)$ & NR & $28.3(1.57)$ & $4.1(3.08)$ \\
\hline & & & $\begin{array}{l}\text { Safinamide } \\
100 \text { mg/day }\end{array}$ & 80 & $53(23)$ & 67.5 & $22.5(9.28)$ & NR & $29.0(1.20)$ & $4.1(3.50)$ \\
\hline & & & placebo & 78 & 55.5 (19.5) & 47 & $21.0(9.73)$ & NR & $28.3(1.53)$ & $4.4(3.14)$ \\
\hline \multirow{3}{*}{ Borgohain et al. 2013} & \multirow{3}{*}{$\mathrm{RCT}$} & \multirow{3}{*}{24 weeks } & $\begin{array}{l}\text { Safinamide } \\
100 \text { mg/day }\end{array}$ & 224 & $60.1(9.19)$ & 72.8 & $28.3(13.30)$ & $4.0(0.72)$ & NR & $6.0(3.54)$ \\
\hline & & & $\begin{array}{l}\text { Safinamide } \\
50 \text { mg/day }\end{array}$ & 223 & $60.1(9.65)$ & 70.4 & $27.3(12.66)$ & $4.0(0.70)$ & NR & $6.0(3.70)$ \\
\hline & & & Placebo & 222 & $59.4(9.41)$ & 72.1 & $28.7(12.02)$ & $4.0(0.66)$ & NR & $5.9(3.70)$ \\
\hline \multirow[t]{2}{*}{ Schapira et al. 2016} & \multirow[t]{2}{*}{$\mathrm{RCT}$} & \multirow[t]{2}{*}{24 weeks } & $\begin{array}{l}\text { Safinamide } \\
100 \text { mg/day }\end{array}$ & 274 & $61.7(9.0)$ & 62.4 & $22.4(11.8)$ & $3(1.1)$ & $28.7(1.5)$ & $4.7(4.0)$ \\
\hline & & & placebo & 163 & $62.1(8.9)$ & 59.3 & $23.4(12.9)$ & $3(1.1)$ & $28.6(1.6)$ & $5.0(4.1)$ \\
\hline \multirow{3}{*}{ Stoochi et al. 2004} & \multirow{3}{*}{$\mathrm{RCT}$} & \multirow{3}{*}{12 weeks } & $\begin{array}{l}\text { Safinamide } \\
90 \mathrm{mg} / \text { day }\end{array}$ & 34 & $45.3(18.9)$ & NR & $16.9(7.4)$ & NR & NR & NR \\
\hline & & & $\begin{array}{l}\text { Safinamide } \\
40 \text { mg/day }\end{array}$ & 33 & $45(19.1)$ & NR & $17.6(7.5)$ & NR & NR & NR \\
\hline & & & placebo & 34 & $45.3(18.9)$ & NR & $17.1(8.6)$ & NR & NR & NR \\
\hline \multirow{3}{*}{ Borgohain et al. 2014} & \multirow{3}{*}{$\mathrm{RCT}$} & \multirow{3}{*}{24 weeks } & $\begin{array}{l}\text { Safinamide } \\
50 \text { mg/day }\end{array}$ & 223 & $43(19.3)$ & 70.4 & $27.3(12.66)$ & NR & NR & $5.3(3.75)$ \\
\hline & & & $\begin{array}{l}\text { Safinamide } \\
100 \text { mg/day }\end{array}$ & 224 & $45(20.1)$ & 72.8 & $28.3(13.30)$ & NR & NR & $5.0(3.43)$ \\
\hline & & & Placebo & 222 & $42(18.9)$ & 72.1 & $28.7(12.02)$ & NR & NR & $5.5(4.01)$ \\
\hline
\end{tabular}

${ }^{*}$ Continuous outcomes presented as mean (SD). RCT, randomized controlled trial; UPDRS III; Unified Parkinson's Disease Rating Scale part three; CGI-S, Clinical Global Impression scale - Severity of IIIness; MMSE, Mini-Mental State Examination; HAM-D, Hamilton Depression Rating Scale; NR, not reported.

DRS score. The overall MD between the two groups from baseline to endpoint in terms of change in "DRS score" did not favor either of the two groups (MD $-0.14 \mathrm{~h}, 95 \%$ CI $[-0.36$ to 0.08 ], Figure $4 \mathrm{E})$. Pooled studies were homogenous $(\mathrm{P}=0.15)$.

CGI severity. The overall MD between the two groups from baseline to endpoint in terms of change in "CGI severity" favored safinamide over placebo (MD - $0.18 \mathrm{~h}, 95 \% \mathrm{CI}$ [-0.24 to -0.12$]$, Figure 4F). Pooled studies were homogenous $(\mathrm{P}=0.70)$.

$P D Q-39$. The overall MD between the two groups from baseline to endpoint in terms of change in "PDQ-39" favored safinamide over placebo (MD -1.59 h, 95\% CI [-2.56 to -0.61], Figure 4G). Pooled studies were homogenous $(\mathrm{P}=0.35)$.

HAM-D. The overall MD between the two groups from baseline to endpoint in terms of change in "HAM-D" favored safinamide over placebo (MD -0.35 h, 95\% CI [-0.64 to -0.06], Figure 4H). Pooled studies were homogenous $(\mathrm{P}=0.88)$.

MMSE. The overall mean difference between the two groups from baseline to endpoint in terms of change in "MMSE" favored safinamide over placebo (MD -0.16 h, 95\% CI [-0.36 to -0.05], Figure 4L). Pooled studies were homogenous $(\mathrm{P}=0.79)$.

Adverse events. The following adverse events were reported in the included studies: Back pain, cataeacts, dizziness, hypertension, dyskinesia, headaches, and worsening of Parkinson's disease, as well as discontinuation due to treatment emergent adverse events (TEAEs), including serious TEAEs, serious drug-related TEAEs, and any TEAEs.

(A) Back pain

Seven studies reported back pain. The pooled meta-analysis did not favor either of the two groups (RR 0.75, 95\% CI [0.56 to $1.02]$, Figure $5 \mathrm{~A})$. Pooled studies were homogenous $(\mathrm{P}=0.46)$. 


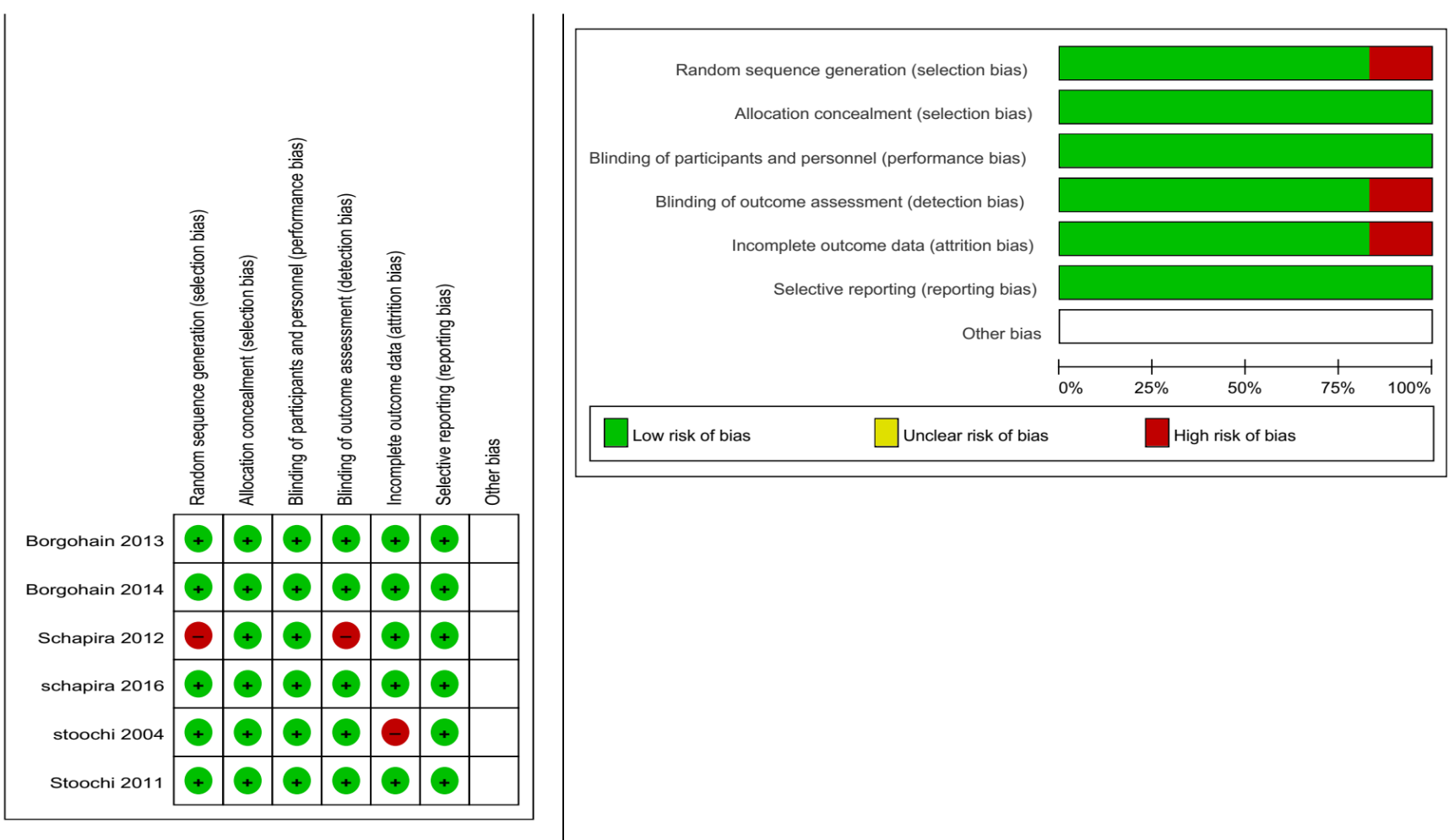

Figure 2. Summary of risk bias according to Cochrane Risk of Bias assessment tool.

(B) Cataracts

Six studies reported cataracts. The pooled meta-analysis did not favor either of the two groups (RR 0.95, 95\% CI [0.69 to 1.31], Figure $5 \mathrm{~B})$. Pooled studies were homogenous $(\mathrm{P}=0.81)$.

\section{(C) Dizziness}

Five studies reported dizziness. The pooled meta-analysis did not favor either of the two groups (RR 0.69 , 95\% CI [0.36 to $1.32]$, Figure 5C). Pooled studies were homogenous $(\mathrm{P}=0.85)$.

(D) Hypertension

Seven studies reported hypertension. The pooled meta-analysis did not favor either of the two groups (RR 1.42, 95\% CI $[0.99$ to 2.03], Figure 5D). Pooled studies were homogenous ( $\mathrm{P}=0.82)$.

\section{(E) Dyskinesia}

Seven studies reported dyskinesia. The pooled meta-analysis showed increase of dyskinesia in patients receiving placebo compared to safinamide (RR $1.50,95 \%$ CI [1.25 to 1.80$]$, Figure 6E). Pooled studies were homogenous $(\mathrm{P}=0.10)$.

\section{(F) Headache}

Five studies reported headaches. The pooled meta-analysis did not favor either of the two groups (RR 1.10, 95\% CI [0.79 to 1.53], Figure 6F). Pooled studies were homogenous $(\mathrm{P}=0.70)$.

(G) Worsening Parkinson's disease

Seven studies reported patients with worsening of Parkinson's disease during the study. The pooled meta-analysis did not favor either of the two groups (RR 0.82, 95\% CI [0.65 to 1.03], Figure $6 \mathrm{G})$. Pooled studies were homogenous $(\mathrm{P}=0.54)$.
(H) TEAEs leading to discontinuation

Nine studies reported the number of patients with TEAEs leading to discontinuation of the study. The pooled meta-analysis did not favor either of the two groups (RR $1.05,95 \%$ CI [0.75 to 1.46], Figure $6 \mathrm{H})$. Pooled studies were homogenous $(\mathrm{P}=1.00)$.

(I) Serious drug-related TEAEs

Three studies reported the number of patients with serious drug-related adverse events. The pooled meta-analysis did not favor either of the two groups (RR $0.72,95 \%$ CI [0.32 to 1.62], Figure 7I). Pooled studies were homogenous $(\mathrm{P}=0.32)$.

\section{(L) Any drug-related TEAEs}

Five studies reported the number of patients with any drugrelated TEAEs. The pooled meta-analysis showed an increase in the number of patients with any drug-related adverse events in the placebo group compared to the safinamide group (RR $1.19,95 \%$ CI [1.03 to 1.36], Figure 7L). Pooled studies were homogenous $(\mathrm{P}=0.36)$.

\section{(M) Any TEAEs}

Seven studies reported the number of the patients with any TEAEs. The pooled meta-analysis did not favor either of the two groups (RR 0.98, 95\% CI [0.93 to 1.02], Figure 7M). Pooled studies were homogenous $(\mathrm{P}=0.88)$.

\section{(N) Serious TEAEs}

Nine studies reported the number of the patients with serious TEAEs. The pooled meta-analysis did not favor either of the two groups (RR 1.02, 95\% CI [0.81 to 1.28], Figure 7N). Pooled studies were homogenous $(\mathrm{P}=0.38)$. 


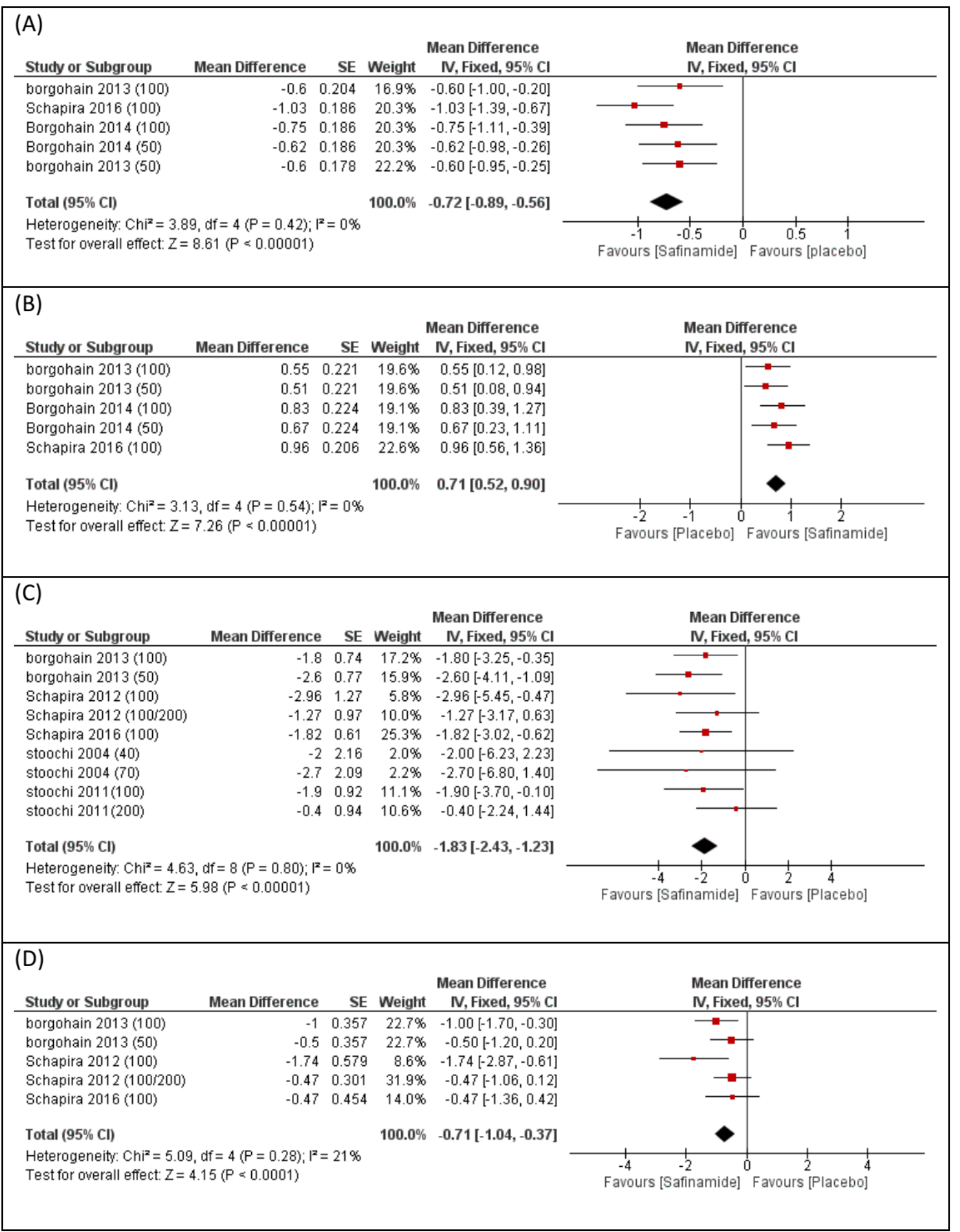

Figure 3. Forest plot of the mean difference and 95\% confidence interval of the following outcome; (A) Off time, (B) On-time without troublesome dyskinesia, (C) UPDRS-III, (D) UPDRS-II. 


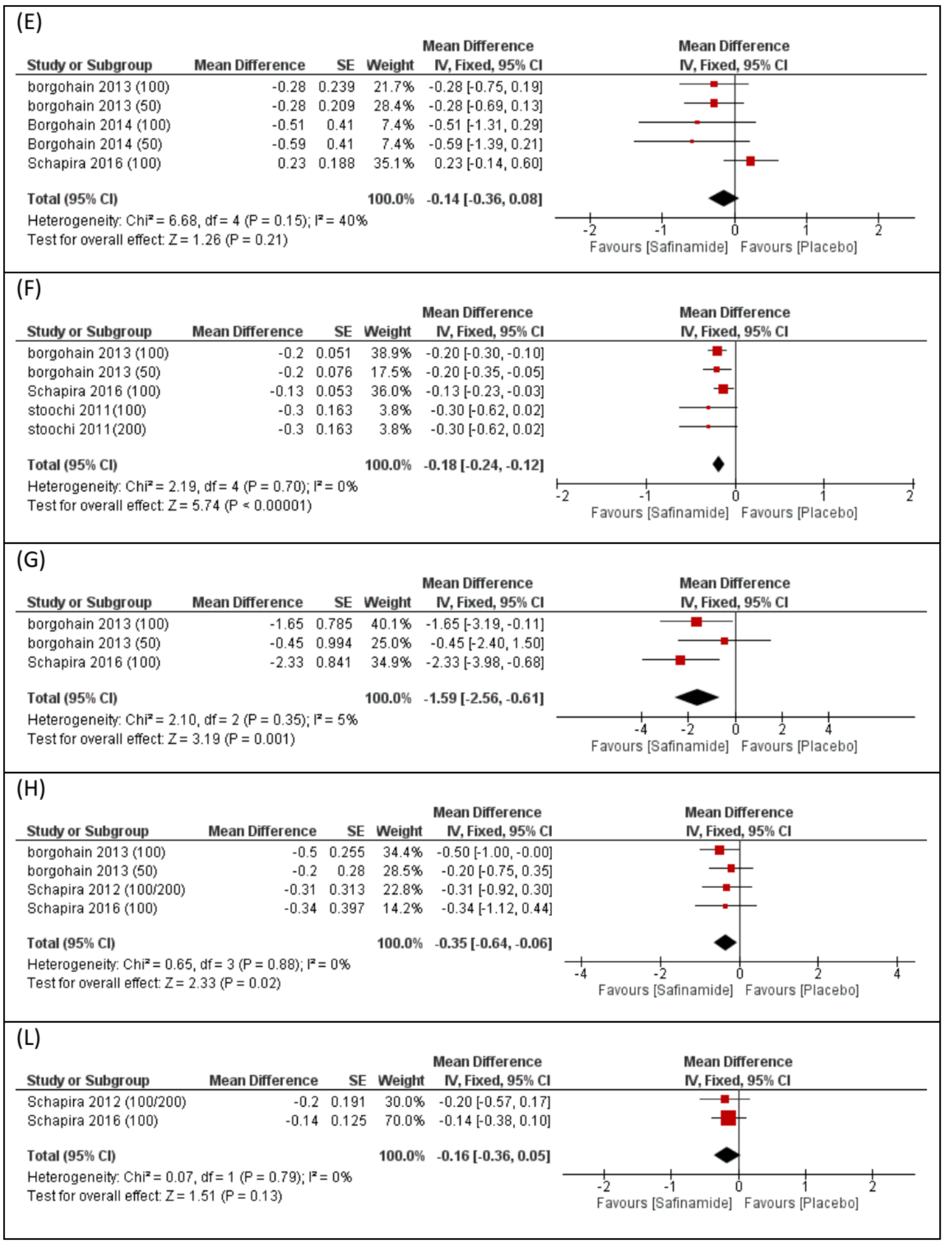

Figure 4. Forest plot of the mean difference and 95\% confidence interval of the following outcomes; (E) DRS, (F) CGI-S, (G) PDQ-39, (H) HAM-D, (L) MMSE. 


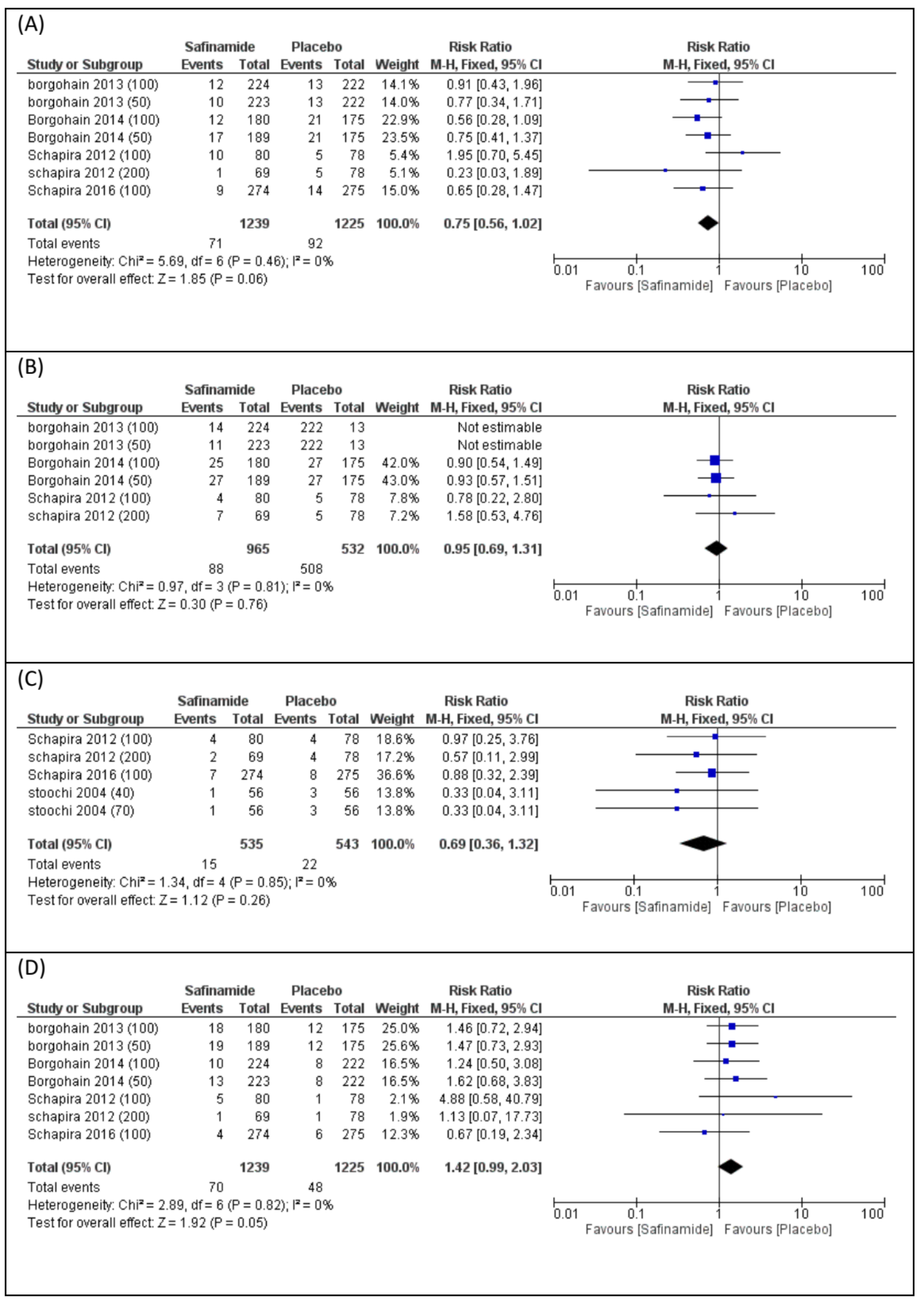

Figure 5. Forest plot presentation of Meta-Analysis for the Following Adverse Events of Safinamide; (A) Back pain, (B) Cataract, (C) Dizziness, and (D) Hypertension. 


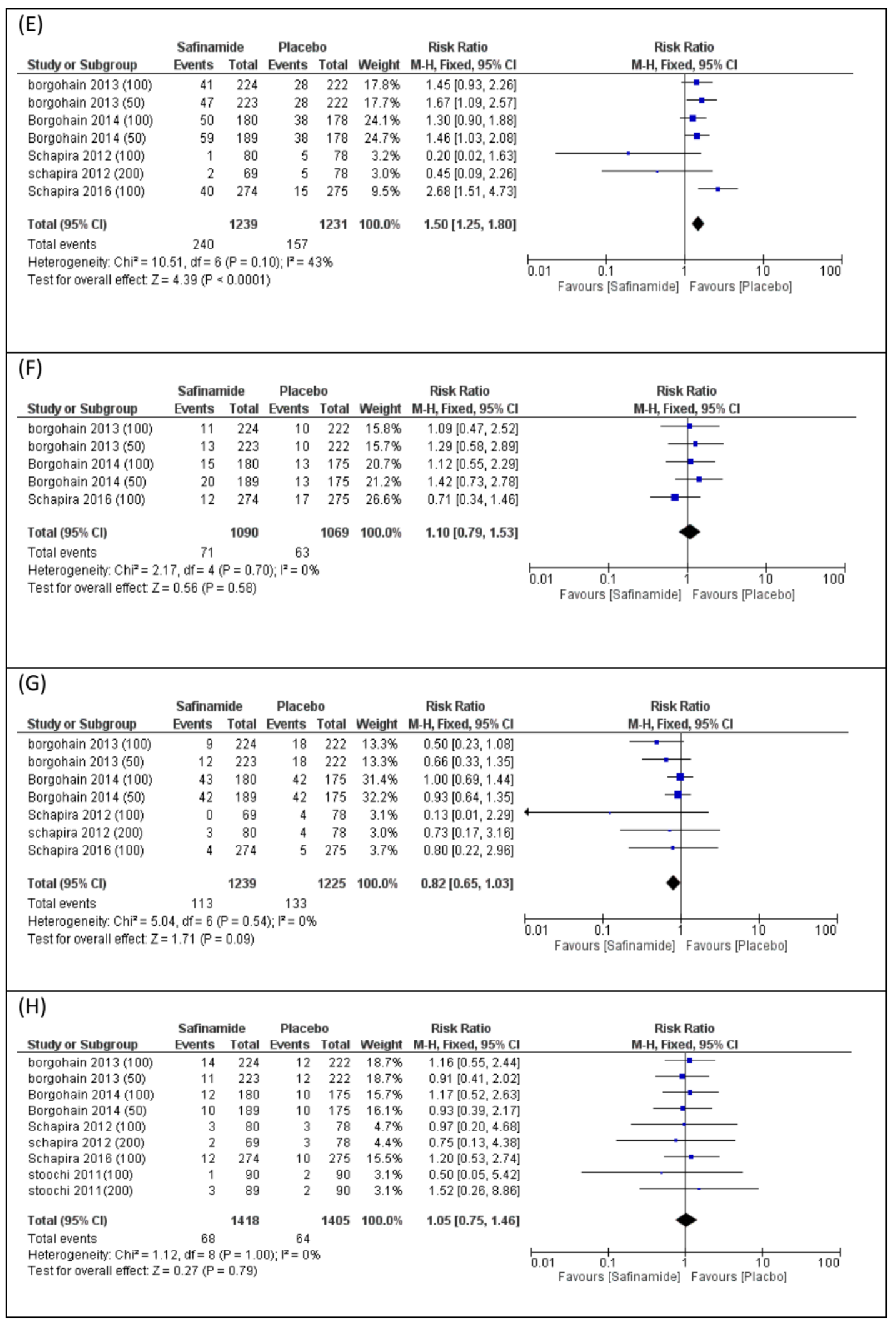

Figure 6. Forest plot presentation of Meta-Analysis for the Following Adverse Events of Safinamide; (E) Dyskinesia, (F) Headache, (G) Worsening Parkinson's disease, and (H) TEAE's leads to discontinuation. 


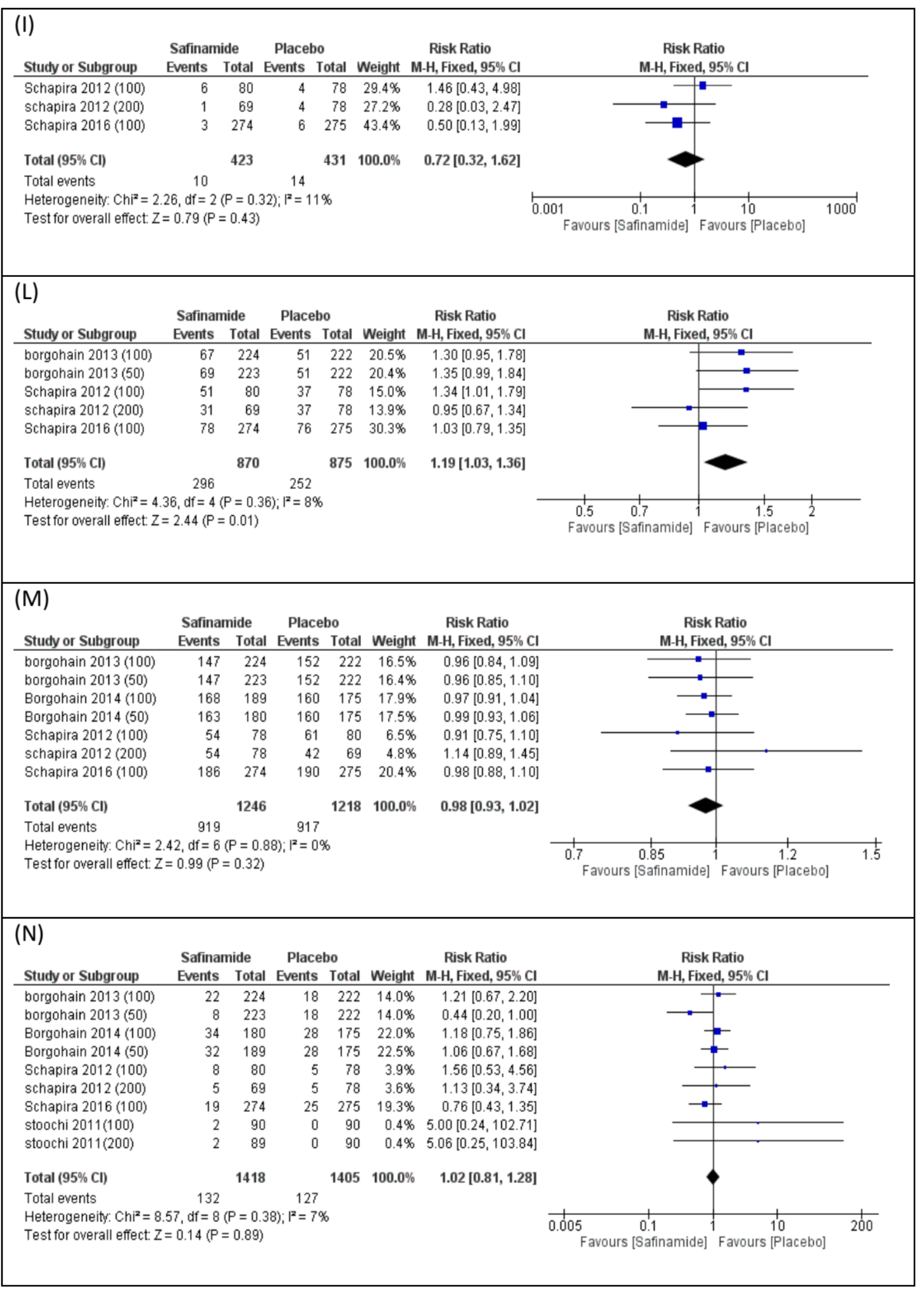

Figure 7. Forest plot presentation of Meta-Analysis for the Following Adverse Events of Safinamide; (I) serious drug related TEAE's, (L) any study drug related TEAE's, (M) any TEAE's, and (N) Serious TEAE's. 
Risk of bias across studies

As showed in Figure 8, funnel plots of UPDRS III, off-time, on-time without troublesome dyskinesia, and UPDRS II show no significant publication bias across studies.

\section{Discussion}

Summary of evidence

The pooled meta-analysis of six studies provides a class I evidence that using safinamide as add-on therapy for Parkinson's disease is very effective and well tolerated. The meta-analysis shows that safinamide improves motor fluctuations, which is a main side effect of anti-Parkinson's medications, as reported by patient diaries and measured by "on time without troublesome dyskinesia", "off-time", and UPDRS III score. This novel drug is also improving the quality of life of Parkinson's disease patients, as measured by the UPDRS II scale, the PDQ-39 questionnaire, HAM-D, and MMSE.
Regarding tolerability, safinamide is a well-tolerated drug and despite increasing the risk of some adverse events such as dyskinesia, which was higher in the safinamide group than the placebo $^{10-14}$, the pooled meta-analysis of RRs of adverse events did not show any statistical significance between the two groups of comparison.

\section{Previous studies}

The results obtained from the meta-analysis are consistent with the results of the previous randomized controlled trials in terms of outcomes measuring motor fluctuations and quality of life. "On time without troublesome dyskinesia" and "off-time" are the main outcomes to evaluate motor fluctuations and were mentioned in Schapira et al. (2016) with (100 mg daily dose), Borgohain et al. (2013 and 2014) with doses of 50 and $100 \mathrm{mg}$ daily. In all the previously mentioned studies, "on time without troublesome dyskinesia" favored the safinamide group over the
(A)

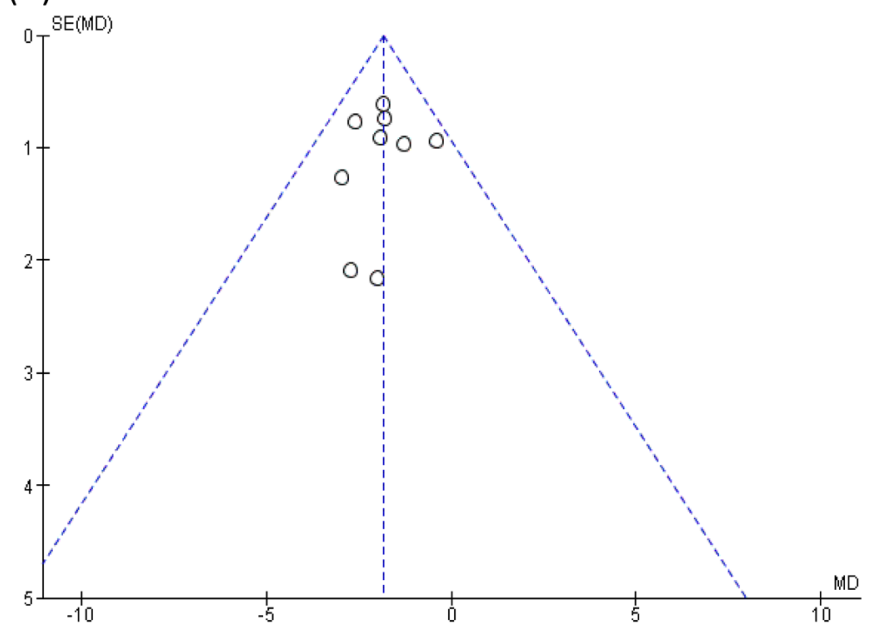

(B)

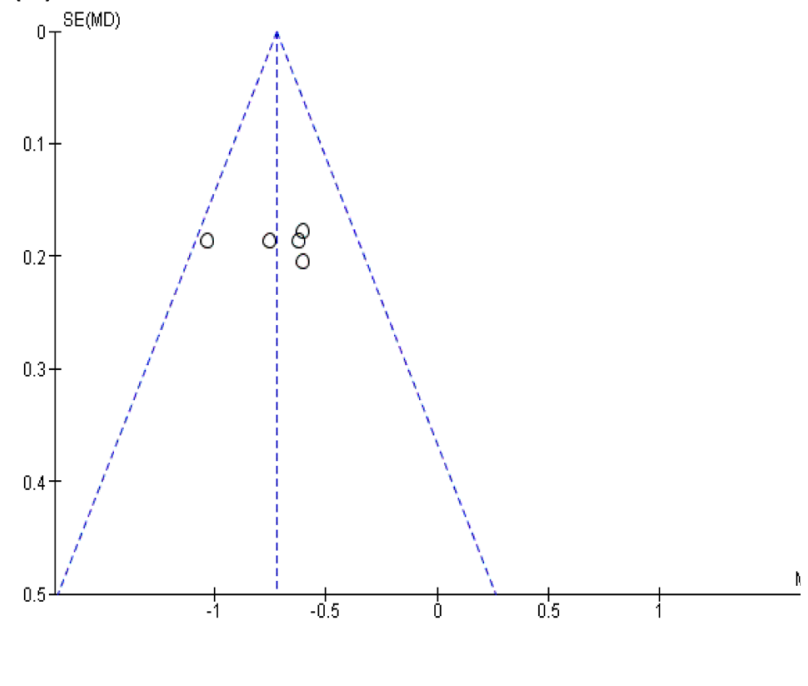

\section{(C)}

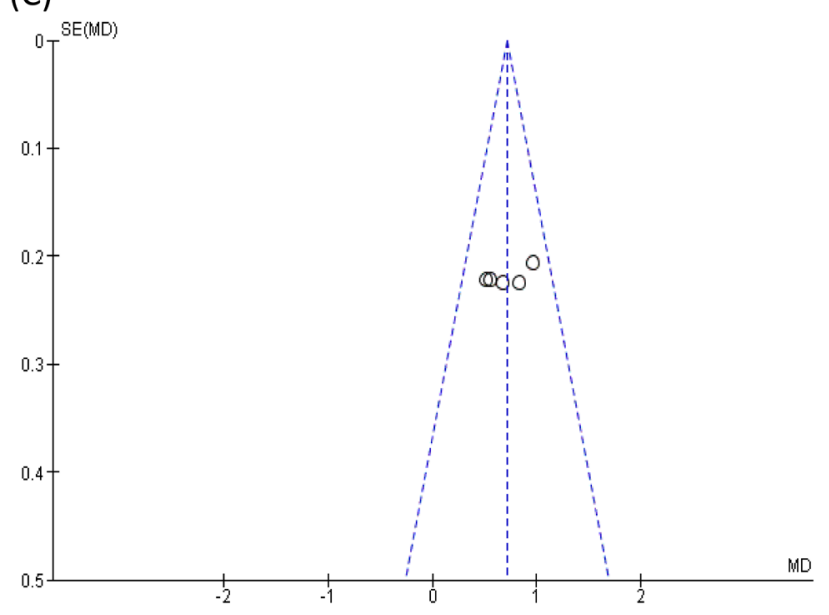

(D)

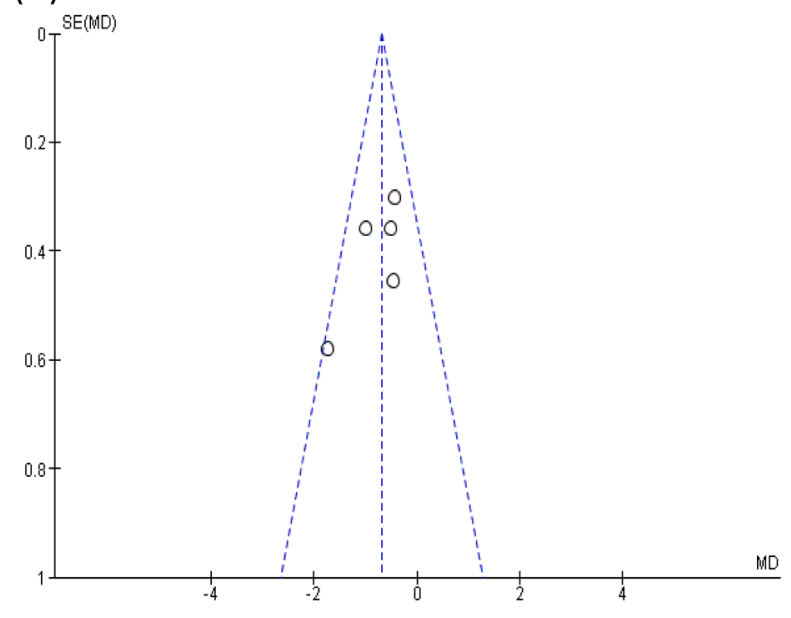

Figure 8. Funnel plots for publication bias for (A) UPDRS III, (B) Off-time, (C) on-time without troublesome dyskinesia, and (D) UPDRS II. 
placebo group ${ }^{12-14}$. In addition, the mean difference of "off-time" in all studies favored the safinamide group and this result was consistent with the pooled meta-analysis of included studies ${ }^{12-14}$.

The UPDRS III is a very important scale for evaluating the motor symptoms in Parkinson's patients. Despite the results of Stoochi et al. (2011) (200mg daily dose), Stoochi et al. (2004) (40mg and 70mg daily doses), and Schapira et al. (2012) (pooled doses of $100 \mathrm{mg}$ and $200 \mathrm{mg}$ daily doses) ${ }^{9-11}$, which showed no statistical significance between safinamide and placebo groups, the pooled meta-analysis showed that the UPDRS III score favors safinamide over placebo. The results of the DRS score in the included studies did not favor safinamide over placebo and the pooled meta-analysis did not favor one group either.

Quality of life in Parkinson's disease patients is measured by UPDRS II, PDQ-39, HAM-D, and MMSE scores. The studies that mentioned the outcomes of quality of life showed results consistent with the pooled meta-analysis that the use of safinamide is preferable to placebo ${ }^{10,11,14}$, except MMSE scores which were mentioned in Schapira et al. (2016), and Schapira et al. (2012) $)^{11,14}$ and showed no statistical significance between safinamide and placebo in both the included studies and the pooled meta-analysis.

\section{Strengths of the study}

The strengths of the meta-analysis are the following: 1) multiple search engines were searched and all the possible sources of studies to be included were covered; 2) clear eligibility criteria were provided; 3) multiple reviewers revised every step to ensure accuracy; 4) during the preparation of this manuscript, the PRISMA guidelines were followed; 5) the study was conducted according to the guidelines of the Cochrane Handbook for Systematic Reviews of Interventions in a strict way; 6) the randomized controlled trials included data of high validity and acceptable quality, as indicated by the risk of bias assessment.

\section{Limitations of the study}

The meta-analysis limitations are the following: A) some studies, such as as Stoochi et al. (2004), Stoochi et al. (2011), and Schapira et al. (2012) $)^{9-11}$ did not mention outcomes such as "on-time without troublesome dyskinesia" and "off-time", which are important measurements for motor symptoms evaluation; B) there was no standardization in the reporting of adverse events in the included studies; C) there was a high risk of bias in some studies, namely as Stoochi et al. (2004) ${ }^{9}$ and Schapira et al. $(2012)^{11}$.
Implications for future research

Based on the results of the study, future randomized controlled trials with different doses are recommended to investigate the efficacy of safinamide for Parkinson's disease patients with motor fluctuations as a side effect of anti-Parkinson's medications.

\section{Conclusions}

Despite the evidence provided by this meta-analysis, demonstrating the efficacy of safinamide as add-on therapy for treatment of motor complications of anti-Parkinson's disease medications, future studies are still needed to confirm the safety and efficacy of this novel drug.

\section{Data availability}

Underlying data

All data underlying the results are available as part of the article and no additional source data are required.

\section{Extended data}

Open Science Framework: A systematic review and metaanalysis of safety and efficacy of Safinamide for motor fluctuations in patients with Parkinson's disease. https://doi. org/10.17605/OSF.IO/T6H9J ${ }^{19}$

This project contains the following extended data:

- Data extraction form.xlsx

- Spreadsheets in .xlsx format containing extracted data for drug efficacy outcomes including adverse events

\section{Reporting guidelines}

Open Science Framework: A systematic review and metaanalysis of safety and efficacy of Safinamide for motor fluctuations in patients with Parkinson's disease. https://doi. org/10.17605/OSF.IO/T6H9J ${ }^{19}$

Data are available under the terms of the Creative Commons Zero "No rights reserved" data waiver (CC0 1.0 Public domain dedication).

\section{Acknowledgements}

The author would like to thank Dr. Ahmed Negida (first reviewer), Randa Gamal (second reviewer), and Mohamed Helmy (third reviewer) for their generous support and guidance through the procedure of completing this manuscript (searching, screening, and data extraction processes).
1. Marras C, Beck JC, Bower JH, et al: Prevalence of Parkinson's disease across North America. NPJ Parkinsons Dis. 2018; 4(1): 21. PubMed Abstract | Publisher Full Text | Free Full Text

2. Schapira $\mathrm{AH}$, Emre M, Jenner $\mathrm{P}$, et al:: Levodopa in the treatment of Parkinson's disease. Eur J Neurol. 2009; 16(9): 982-9 PubMed Abstract | Publisher Full Text

3. Ferreira JJ, Katzenschlager R, Bloem BR, et al.: Summary of the recommendations of the EFNS/MDS-ES review on therapeutic management of 
Parkinson's disease. Eur J Neurol. 2013; 20(1): 5-15. PubMed Abstract | Publisher Full Text

4. Poewe WH, Lees AJ, Stern GM: Low-dose L-dopa therapy in Parkinson's disease: a 6-year follow-up study. Neurology. 1986; 36(11): 1528-30. PubMed Abstract | Publisher Full Text

5. Rinne UK: Treatment of Parkinson's disease: problems with a progressing disease. J Neural Transm. 1981; 51(1-2): 161-74. PubMed Abstract | Publisher Full Tex

6. Obeso JA, Olanow CW, Nutt JG: "Levodopa motor complications in Parkinson's disease." Trends Neurosci. 2000; 23(10 Suppl): S2-S7. PubMed Abstract | Publisher Full Text

7. Marzo A, Dal Bo L, Monti NC, et al:: Pharmacokinetics and pharmacodynamics of safinamide, a neuroprotectant with antiparkinsonian and anticonvulsant activity. Pharmacol Res. 2004; 50(1): 77-85. PubMed Abstract | Publisher Full Text

8. Schapira $\mathrm{AH}$ : Safinamide in the treatment of Parkinson's disease. Expert Opin Pharmacother. 2010; 11(13): 2261-8. PubMed Abstract | Publisher Full Text

9. Stocchi F, Arnold G, Onofrj M, et al.: Improvement of motor function in early Parkinson disease by safinamide. Neurology. 2004; 63(4): 746-8. PubMed Abstract | Publisher Full Text

10. Stocchi F, Borgohain R, Onofrj M, et al:: A randomized, double-blind, placebocontrolled trial of safinamide as add-on therapy in early Parkinson's disease patients. Mov Disord. 2012; 27(1): 106-12. PubMed Abstract | Publisher Full Text

11. Schapira $A H$, Stocchi $F$, Borgohain $R$, et al.: Long-term efficacy and safety of safinamide as add-on therapy in early Parkinson's disease. Eur J Neurol. 2013; 20(2): 271-80

PubMed Abstract | Publisher Full Text

12. Borgohain R, Szasz J, Stanzione $P$, et al.: Randomized trial of safinamide add-on to levodopa in Parkinson's disease with motor fluctuations. Mov Disord. 2014 29(2): 229-37.

PubMed Abstract | Publisher Full Text | Free Full Text

13. Borgohain R, Szasz J, Stanzione $P$, et al.: Two-year, randomized, controlled study of safinamide as add-on to levodopa in mid to late Parkinson's disease. Mov Disord. 2014; 29(10): 1273-80. PubMed Abstract | Publisher Full Text

14. Schapira AH, Fox SH, Hauser RA, et al:: Assessment of Safety and Efficacy of Safinamide as a Levodopa Adjunct in Patients With Parkinson Disease and Motor Fluctuations: A Randomized Clinical Trial. JAMA Neurol. 2017; 74(2): 216-224. PubMed Abstract | Publisher Full Text

15. Liberati A, Altman DG, Tetzlaff J, et al.: The PRISMA statement for reporting systematic reviews and meta-analyses of studies that evaluate health care interventions: explanation and elaboration. PLoS Med. 2009; 6(7): e1000100. PubMed Abstract | Publisher Full Text | Free Full Text

16. Higgins JP, Green S: Cochrane handbook for systematic reviews of interventions. John Wiley \& Sons. 2011.

Publisher Full Text

17. Whitlock EP, Lopez SA: Methods Guide for Comparative Effectiveness Reviews.

18. Clarke $\mathrm{CE}$, Patel $\mathrm{S}$, Ives $\mathrm{N}$, et al.: Clinical effectiveness and cost-effectiveness of physiotherapy and occupational therapy versus no therapy in mild to moderate Parkinson's disease: a large pragmatic randomized controlled tria (PD REHAB). Southampton (UK): NIHR Journals Library. (Health Technology Assessment, No. 20.63.) Appendix 1, UK Parkinson's Disease Society Brain Bank Diagnostic Criteria. 2016. Reference Source

19. Aziz MA: A systematic review and meta-analysis of safety and efficacy of safinamide for motor fluctuations in patients with Parkinson's disease. 2019; http://www.doi.org/10.17605/OSF.IO/T6H9J

20. Higgins JP, Altman DG, Gøtzsche PC, et al.: The Cochrane Collaboration's tool for assessing risk of bias in randomised trials. BMJ. 2011; 343: d5928. PubMed Abstract | Publisher Full Text | Free Full Text

21. Movement Disorder Society Task Force on Rating Scales for Parkinson's Disease. The unified Parkinson's disease rating scale (UPDRS): status and recommendations. Mov Disord. 2003; 18(7): 738-50. PubMed Abstract | Publisher Full Text

22. Goetz CG, Nutt JG, Stebbins GT: The unified dyskinesia rating scale: presentation and clinimetric profile. Mov Disord. 2008; 23(16): 2398-403. PubMed Abstract | Publisher Full Text

23. Guy W: ECDEU assessment manual for psychopharmacology. US Department of Health, and Welfare. 1976: 534-537. Reference Source

24. Ramaker C, Marinus J, Stiggelbout AM, et al.: Systematic evaluation of rating scales for impairment and disability in Parkinson's disease. Mov Disorder. 2002; 17(5): 867-76. PubMed Abstract | Publisher Full Text

25. Jenkinson C, Fitzpatrick R, Peto V, et al.: The Parkinson's Disease Questionnaire (PDQ-39): development and validation of a Parkinson's disease summary index score. Age Ageing. 1997; 26(5): 353-7. PubMed Abstract | Publisher Full Text

26. Pangman VC, Sloan J, Guse L: An examination of psychometric properties of the mini-mental state examination and the standardized mini-mental state examination: implications for clinical practice. Appl Nurs Res. 2000; 13(4): 209-13. PubMed Abstract | Publisher Full Text

27. Hamilton M: A rating scale for depression. J Neurol Neurosurg Psychiatry. 1960 23: 56-62.

PubMed Abstract | Publisher Full Text | Free Full Text 


\section{Open Peer Review}

\section{Current Peer Review Status:}

\section{Version 1}

Reviewer Report 06 May 2020

https://doi.org/10.5256/f1000research.23538.r58806

(C) 2020 Negida A. This is an open access peer review report distributed under the terms of the Creative Commons Attribution License, which permits unrestricted use, distribution, and reproduction in any medium, provided the original work is properly cited.

\section{Ahmed Negida}

${ }^{1}$ School of Pharmacy and Biomedical Sciences, University of Portsmouth, Portsmouth, UK

2 Zagazig University Hospitals, Zagazig University, Zagazig, Egypt

The article describes a systematic review and meta-analysis of published studies on the Safenamide for the treatment of motor fluctuations in Parkinson's Disease.

First, the topic is interesting because currently, there is an unmet clinical need to find potential agents that decrease the motor fluctuations and the LED in PD midstage and late-stage PD.

Second, the methodology is clear and in accordance with the Cochrane handbook guidelines, while the manuscript is well-written in compliance with the standard reporting guidelines (PRISMA statement) - endorsed by the ICMJEs.

The statistical analysis was properly done and the data analysis interpretation and discussion are sufficient.

I do not find any major concerns in the article; I believe it worth the publication. No further changes are required from my point of view.

Are the rationale for, and objectives of, the Systematic Review clearly stated?

Yes

Are sufficient details of the methods and analysis provided to allow replication by others? Yes

Is the statistical analysis and its interpretation appropriate?

Yes

Are the conclusions drawn adequately supported by the results presented in the review? Yes 
Competing Interests: No competing interests were disclosed.

Reviewer Expertise: I'm a medical doctor, holding an MD degree, and currently doing a Ph.D. in Parkinson's Disease treatment (the same scope of this manuscript). I have several similar publications in the field.

I confirm that I have read this submission and believe that I have an appropriate level of expertise to confirm that it is of an acceptable scientific standard.

Reviewer Report 27 April 2020

https://doi.org/10.5256/f1000research.23538.r61383

(C) 2020 Borgohain $\mathbf{R}$ et al. This is an open access peer review report distributed under the terms of the Creative Commons Attribution License, which permits unrestricted use, distribution, and reproduction in any medium, provided the original work is properly cited.

\section{Rupam Borgohain}

Department of Neurology, Nizam's Institute of Medical Sciences, Hyderabad, India

\section{Rukmini Kandadai}

Department of Neurology, Nizam's Institute of Medical Sciences, Hyderabad, India

The authors published a systematic review and meta-analysis of safety and efficacy of safinamide for motor fluctuations in patients with Parkinson's disease.

The meta-analysis is the first one and has been conducted well. It demonstrates the efficacy and safety of safinamide in Parkinson's disease and its value in patients with dyskinesias.

Safinamide can be used in early PD as a single drug or in combination with dopamine agonist. It can be an add on in mid-late PD for motor fluctuations.

The methodology states that the studies which did not use safinamide as an add on therapy for motor fluctuations in PD would exclude some studies included.

However, the studies included in the meta-analysis include patients with early PD as well as those with mid-late PD.

Early PD patients do not have motor fluctuations, dyskinesias, are less likely to have depression, cognitive impairment and thus this subset may undervalue the actual effect of safinamide.

Are the rationale for, and objectives of, the Systematic Review clearly stated? Partly

Are sufficient details of the methods and analysis provided to allow replication by others? Partly

Is the statistical analysis and its interpretation appropriate?

Partly

Are the conclusions drawn adequately supported by the results presented in the review? 
Partly

Competing Interests: No competing interests were disclosed.

Reviewer Expertise: Movement disorders, Botulinum toxin, Deep brain stimulation

We confirm that we have read this submission and believe that we have an appropriate level of expertise to confirm that it is of an acceptable scientific standard.

Reviewer Report 24 March 2020

https://doi.org/10.5256/f1000research.23538.r61382

(C) 2020 Stocchi $\mathbf{F}$. This is an open access peer review report distributed under the terms of the Creative Commons Attribution License, which permits unrestricted use, distribution, and reproduction in any medium, provided the original work is properly cited.

\section{Fabrizio Stocchi}

Center for Parkinson's Disease, IRCCS San Raffaele Pisana, Rome, Italy

The authors published a systematic review and meta-analysis of safety and efficacy of safinamide for motor fluctuations in patients with Parkinson's disease. There are other review on safinamide but the meta-analysis can be interested. However the paper must be revised addressing some important issues:

Introduction:

Non-motor symptoms should be better addressed and ref. implemented and revised.

Within the other treatment, COMTI are not mentioned

The meta-analysis is well conducted and gave a number of good information, but there are some problems:

The studies were grouped according to the presence of the end-point. However for UPDRS III studies with different population were grouped together, moreover in some of these studies UPDR III was the primary end-point but for the other studies it was a secondary endpoint. UPDRS scored in an early population give information about the effect of the drug on symptoms, in fluctuators it does not.

Other parameter were influenced by the dose in the original study (PDQ39, UPDRS II) but putting all the patents together this effect does not emerge giving the false impression that the drug is always efficacious. These aspects should be carefully addressed and discussed.

Are the rationale for, and objectives of, the Systematic Review clearly stated? Partly

Are sufficient details of the methods and analysis provided to allow replication by others? Partly 
Is the statistical analysis and its interpretation appropriate?

Partly

Are the conclusions drawn adequately supported by the results presented in the review? Partly

Competing Interests: No competing interests were disclosed.

Reviewer Expertise: Movement disorders, Parkinson's disease, neuropharmacology, clinical trials.

I confirm that I have read this submission and believe that I have an appropriate level of expertise to confirm that it is of an acceptable scientific standard, however I have significant reservations, as outlined above.

The benefits of publishing with F1000Research:

- Your article is published within days, with no editorial bias

- You can publish traditional articles, null/negative results, case reports, data notes and more

- The peer review process is transparent and collaborative

- Your article is indexed in PubMed after passing peer review

- Dedicated customer support at every stage

For pre-submission enquiries, contact research@f1000.com 